\title{
Immobilizing osteogenic growth peptide with and without fibronectin on a titanium surface: effects of loading methods on mesenchymal stem cell differentiation
}

\section{Cen Chen ${ }^{1,2}$ \\ Han $\mathrm{Li}^{\prime}$ \\ Xiangdong Kong ${ }^{2}$ \\ Sheng-Min Zhang' \\ In-Seop Lee ${ }^{2,3}$}

'Advanced Biomaterials and Tissue Engineering Center, Huazhong University of Science and Technology, Wuhan, People's Republic of China; ${ }^{2}$ Bio-X Center, College of Life Sciences, Zhejiang Sci-Tech University, Hangzhou, People's Republic of China; ${ }^{3}$ Institute of Natural Sciences, Yonsei University, Seoul, Korea
Correspondence: In-Seop Lee Institute of Natural Sciences and Institute of Physics and Applied Physics, Yonsei University, I 34 Shinchon-dong, Seodaemoon-gu, Seoul 120-749, Korea $\mathrm{Tel}+82221234806$

Fax +8223133537

Email inseop@yonsei.ac.kr
This article was published in the following Dove Press journal:

International Journal of Nanomedicine

31 December 2014

Number of times this article has been viewed
Abstract: In this study, to improve the osseointegration of implants, osteogenic growth peptide (OGP) and fibronectin (FN) were loaded within mineral, which was formed on titanium, through adsorption and coprecipitation methods. The release profiles of OGP loaded by either adsorption or coprecipitation and the effects of the loading methods to immobilize OGP with and without FN on rat mesenchymal stem cell (rMSC) osteogenic differentiation were studied. The coprecipitation approach slightly reduced the initial burst release, while the adsorption approach provided a more sustained release. Dual loading of OGP and FN further improved cell attachments compared with either OGP or FN alone. Dually loaded OGP and FN also had a positive impact on rMSC proliferation and osteogenic differentiation. The difference in methods of loading OGP with and without $\mathrm{FN}$ also had some effects on osteogenic differentiation. Compared with coprecipitated OGP alone, adsorbed OGP enhanced later differentiation, such as osteocalcin secretion and matrix mineralization. Simultaneously adsorbed OGP and FN led to higher proliferation and higher osteogenic differentiation in both early and late stages compared with sequentially loaded OGP and FN. rMSC culture clearly indicated that simultaneously adsorbed OGP and FN could improve osseointegration, and this treatment represents a potential method for effective surface modification of dental and orthopedic implants.

Keywords: coprecipitation, adsorption, osseointegration

\section{Introduction}

The principal requirement for dental implants is osseointegration, and genuine osseointegration means bonding implants to living bones without the formation of fibrous tissues. ${ }^{1}$ The use of narrow implants and early or even immediate loading requires a higher degree of osseointegration at the early stage of healing. ${ }^{2}$ A variety of surface modification methods have been developed to facilitate osseointegration of titanium implants, including control of the surface topography, ${ }^{3}$ hydroxyapatite coating, ${ }^{4}$ and bioactive molecule (BM) immobilization. ${ }^{5,6}$

Over the last decade, various BM-based strategies have attracted a lot of attention. The loading of laminin, fibroblast growth factor, and bone morphogenic protein- 2 on the surfaces of implants has been proved to enhance mesenchymal stem cell (MSC) attachment, ${ }^{7}$ enhance cell proliferation, ${ }^{8}$ and improve osteogenesis, ${ }^{9}$ respectively. With regard to optimal differentiation of attached cells, the present authors investigated the individual loading of osteogenic growth peptide (OGP) and fibronectin (FN) due to their important roles in osteogenic differentiation and cell adhesion. ${ }^{5,10}$ 
OGP (isoelectric point $=11.4, \mathrm{Mw}=1.5 \mathrm{kDa}$ ) is a short, linear tetradecapeptide (Ala-Leu-Lys-Arg-Gln-Gly-Arg-ThrLeu-Tyr-Gly-Phe-Gly-Gly) found in serum at $\mu \mathrm{mol} / \mathrm{L}$ concentrations. When administered intravenously to animals, OGP promotes the density of newly formed bones and stimulates bone healing. ${ }^{11}$ Bab and Chorev suggest that neither a simple burst release nor sustained release are optimal to stimulate the osteogenic responses because OGP regulates osteocyte proliferation, alkaline phosphatase (ALP) activity, and matrix mineralization via an autoregulated feedback mechanism. ${ }^{12}$

FN is a multifunctional cell adhesive glycoprotein that is present in the extracellular matrix and plasma. Research has shown that FN plays a special role in the process of osseointegration due to its ability to attach cells to extracellular matrix components through integrin receptor interactions. ${ }^{13}$

Bone-like mineral coating has been applied widely onto titanium implants in orthopedic and dental applications to enhance osseointegration and improve bone formation around implants. ${ }^{14}$ Bone-like mineral coatings can also serve as carriers for BMs, ${ }^{15}$ and have been shown to control the release of BMs. ${ }^{16}$ There are many methods for loading BMs with biomimetically formed mineral, such as physical adsorption, covalent binding, and biomimetic coprecipitation, each of which results in different loading efficiencies and release kinetics. ${ }^{17}$ According to the literature, the release of superficially adsorbed BMs from mineral coatings is in a "burst release" fashion, followed by a slower release based on the chemical or physical attraction between the bone-like mineral and the BMs. ${ }^{18}$ Whereas coprecipitation leads to sustained release, ${ }^{19}$ as only a small portion of BMs is released due to the slow degradation characteristic of mineral coatings in physiological conditions. ${ }^{20}$

Luong et al controlled the release of coprecipitated BMs by modulating time points at which BMs were added into the mineralizing fluid. ${ }^{21} \mathrm{Yu}$ and Wei also found that, when bovine serum albumin (BSA) was added to modified simulated body fluid (m-SBF) at the beginning of immersion, only $22 \%$ of coprecipitated BSA was released after 10 days. In comparison, the percentage of BSA release increased to $28 \%$ and $32 \%$ when BSA was added to the m-SBF at 4 and 6 hours after immersion, respectively. ${ }^{22}$

In the present study, we hypothesized that a different release profile would influence the osteogenic differentiation of MSCs, and the cell adhesion molecule FN would further improve the osteogenesis efficiency when it was loaded together with OGP on titanium surfaces.

The bone-like mineral was simply precipitated by immersing an alkali-treated titanium substrate in Dulbecco's phosphate-buffered saline (DPBS) containing $\mathrm{CaCl}_{2}$. The first objective was to examine the physicochemical characteristics and the release profile of OGP loaded by either physical adsorption or coprecipitation. OGP-loaded titanium surfaces were characterized using an environmental scanning electron microscope and X-ray diffraction. The release of OGP was examined using a fluorescent spectrophotometer, since OGP was labeled with a fluorescein isothiocyanate (FITC) tag. The second objective of this study was to investigate how the two different methods of loading OGP with and without FN would affect the osteogenic differentiation of MSCs. DNA content, ALP activity, osteocalcin (OC) secretion, and calcium deposition were evaluated over 4 weeks.

\section{Materials and methods Preparation of alkali-treated titanium}

Commercially pure titanium discs (grade IV; Supra Alloys Inc., Camarillo, CA, USA) with a diameter of $10 \mathrm{~mm}$ and a thickness of $2 \mathrm{~mm}$ were washed by ultrasonic cleaning in pure acetone, ethanol, and distilled water for 15 minutes each, and then were dried at $40^{\circ} \mathrm{C}$. The titanium substrate was then soaked in $5 \mathrm{~mL}$ of $1 \mathrm{M}$ sodium hydroxide $(\mathrm{NaOH})$ aqueous solution at $140^{\circ} \mathrm{C}$ for 6 hours, washed gently with distilled water, and dried at $40^{\circ} \mathrm{C}$. These treated titanium substrates are denoted as "alkali-treated Ti".

\section{Solution and BMs used}

Reagent-grade $\mathrm{CaCl}_{2}(100 \mathrm{mg} / \mathrm{L})$ was dissolved in DPBS (calcium/magnesium free; Thermo Fisher Scientific, Waltham, MA, USA) to prepare the DPBS solution. FN was purchased from Sigma-Aldrich Co. (F2006; St Louis, MO, USA). The synthetic linear OGP and FITC-labeled OGP (FITC-OGP) used in the release experiment were synthesized by GL Biochem (Shanghai) Ltd. (Shanghai, People's Republic of China).

\section{Loading of OGP and/or FN with mineral on $\mathrm{Ti}$ substrate}

Figure 1 shows the two loading procedures of BM, coprecipitation and adsorption. Mineralized control samples were first prepared by immersing alkali-treated $\mathrm{Ti}$ in $5 \mathrm{~mL}$ of DPBS at $37^{\circ} \mathrm{C}$ for 24 hours. For coprecipitation, the mineralized control samples were immersed in $1 \mathrm{~mL}$ of DPBS containing $20 \mu \mathrm{g} \mathrm{OGP}$ at $25^{\circ} \mathrm{C}$ for 24 hours. For adsorption, $20 \mu \mathrm{L}$ of distilled water containing $5 \mu \mathrm{g}$ OGP and/or $8 \mu \mathrm{g}$ FN was dropped onto mineralized control samples and dried in air. All the solutions were sterilized by filtration, using a membrane with a pore size of $0.20 \mu \mathrm{m}$, before use. 


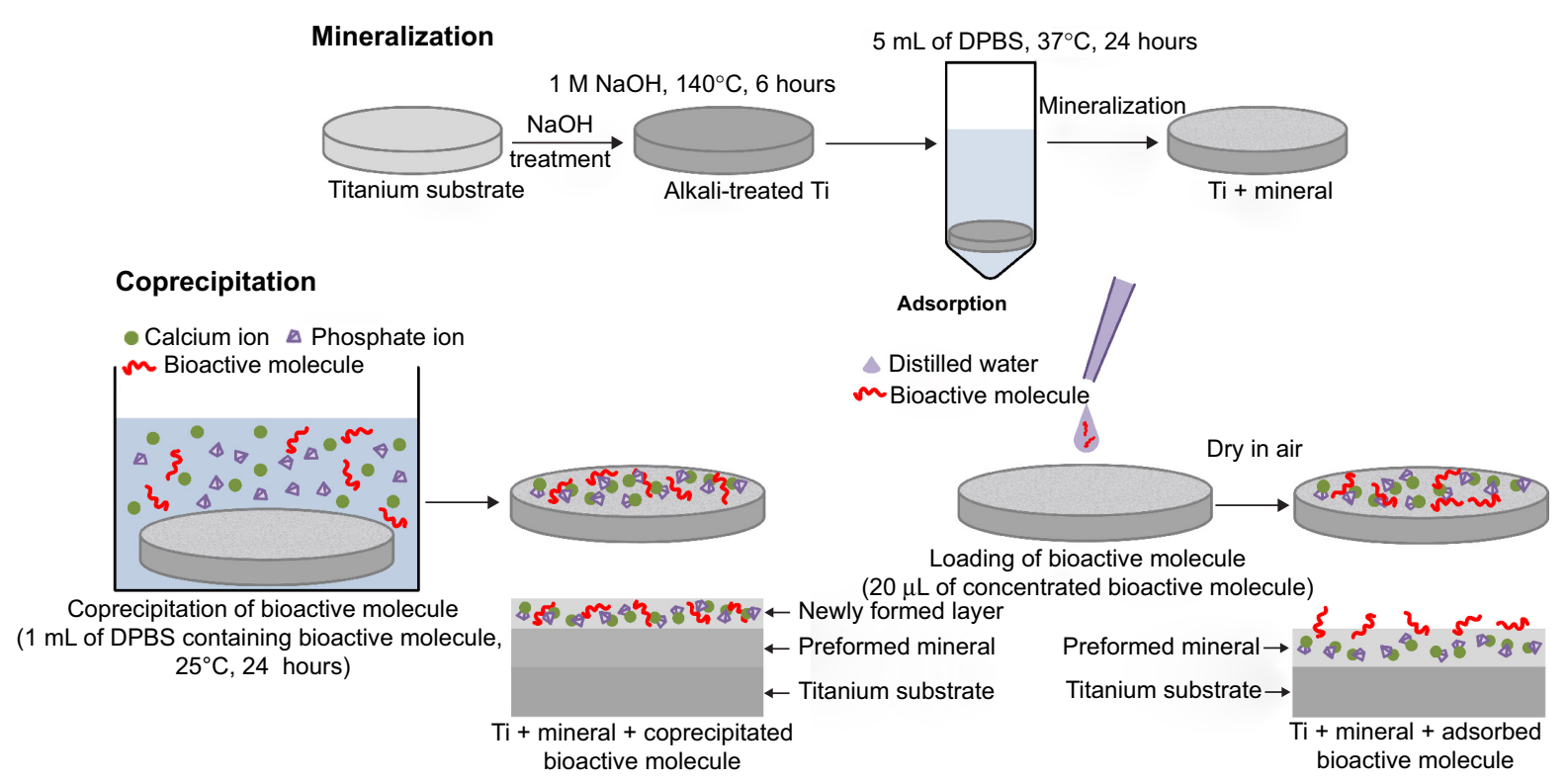

Figure I Sketch map of the loading of bioactive molecules on alkali-treated $\mathrm{Ti}$.

Abbreviations: Alkali-treated Ti, alkali-treated titanium substrate; DPBS, Dulbecco's phosphate-buffered saline.

In order to investigate the physicochemical characteristics and the release profile of OGP loaded by either physical adsorption or coprecipitation, and how the two different methods of loading OGP with and without adsorbed FN affect osteogenic differentiation of the MSCs, the samples were prepared as follows (Table 1): 24-hour mineralization, 24-hour coprecipitation of mineral and OGP $(\mathrm{cO})$; 24-hour mineralization, OGP adsorption (aO); 24-hour mineralization, $\mathrm{FN}$ adsorption $(\mathrm{aF})$; 24-hour mineralization, 24-hour coprecipitation of mineral and OGP, $\mathrm{FN}$ adsorption $(\mathrm{cO} / \mathrm{aF})$; 24-hour mineralization, OGP and FN adsorption (aOF); and 24-hour mineralization (control).

The amount of loaded BMs was quantified using a Micro BCA Protein Assay Kit (Thermo Fisher Scientific, Waltham, MA, USA) according to an adapted version of the manufacturer's protocol. Absorbance was measured at $562 \mathrm{~nm}$ using an ultraviolet/visible spectrophotometer (TU-1810; Persee, Beijing, People's Republic of China) and then was converted to a BM concentration using an albumin standard curve. For the coprecipitation groups, the amount of coprecipitated OGP was determined by subtracting the amount of residual OGP from that of the initially added OGP. For the adsorption groups, we hypothesized that all dropped BMs would be retained on each sample's surface after being dried in air. The amounts of BMs loaded on the samples are listed in Table 1.

\section{Surface analysis and OGP release}

Changes in the surfaces of titanium substrates after alkali treatment, mineralization, and loading of OGP by coprecipitation or adsorption schemes were observed using an environmental scanning electron microscope (Quanta 200; FEI Company, Philips, Netherlands) and thin-film X-ray diffraction (X'Pert PRO; PANalytical, Almelo, Netherlands) using $\mathrm{Cu}-\mathrm{K} \alpha$ radiation over the $2 \theta$ range $10^{\circ}-80^{\circ}$ with a step size of $0.01^{\circ}$.

The release kinetics of coprecipitated OGP or adsorbed OGP from the mineral layer were studied. We chose FITC-OGP for the release experiment, since the FITC tag allowed OGP quantities to be measured with a fluorescent spectrophotometer. The FITC-OGP was coprecipitated or adsorbed on mineralization samples as described in the "Loading of OGP and/or FN with mineral on Ti substrate" section. The samples with coprecipitated or adsorbed OGP

Table I Descriptions of samples and the amount of bioactive molecules loaded on each sample

\begin{tabular}{llll}
\hline Label & Description & $\begin{array}{l}\text { Amount } \\
\text { of loaded } \\
\text { bioactive } \\
\text { molecules } \\
(\mu \mathbf{g})\end{array}$ \\
\cline { 3 - 4 } & FN & OGP \\
\hline Control & Mineralization & - & - \\
$\mathrm{cO}$ & Mineralization, coprecipitation of & - & 5 \\
aO & mineral and OGP & & \\
aF & Mineralization, OGP adsorption & - & 5 \\
$\mathrm{cO} / \mathrm{aF}$ & $\begin{array}{l}\text { Mineralization, FN adsorption } \\
\text { Mineralization, coprecipitation of }\end{array}$ & 8 & - \\
aOF & mineral and OGP, FN adsorption & 8 & 5 \\
\hline
\end{tabular}

Abbreviations: OGP, osteogenic growth peptide; FN, fibronectin. 
were soaked in $1 \mathrm{~mL}$ of phosphate-buffered saline (PBS; Thermo Fisher Scientific, Waltham, MA, USA) at $37^{\circ} \mathrm{C}$ under gentle shaking for 15 days. At each time interval the supernatant was completely collected and fresh PBS was added. The released FITC-OGP in the collected supernatants was measured at $493 \mathrm{~nm}$.

\section{Cultivation and differentiation induction of MSCs}

Sprague Dawley rat MSCs (rMSCs) (Cyagen Biosciences, Guangzhou, People's Republic of China) were thawed and cultured in rMSC growth medium (Cyagen Biosciences) under standard cell culture conditions (a sterile, $37^{\circ} \mathrm{C}$, humidified, $5 \% \mathrm{CO}_{2}$ environment). rMSC growth medium was composed of rMSC basal medium, fetal bovine serum (FBS), glutamine, and penicillin-streptomycin. Stem cells at the fifth passage were used for all the cell culture experiments. The growth medium was changed every 3 days until the cells reached $80 \%-100 \%$ confluence.

Each mineralized control sample was sterilized in $70 \%$ ethanol, washed with distilled water, and placed under ultraviolet light overnight. Experimental samples were prepared as mentioned in the "Loading of OGP and/or FN with mineral on Ti substrate" section using sterilized solutions. For osteogenic differentiation induction, the rMSCs were seeded on samples placed into 48-well culture plates (four or five per group). The rMSCs were cultured to $100 \%$ confluence in the growth medium, and the medium was then changed to mineralizing medium (rMSC osteogenic differentiation basal medium with FBS, glutamine, penicillin-streptomycin, ascorbate, and $\beta$-glycerophosphate). For positive control, rMSCs were seeded on mineralized control, and the growth medium was changed to osteogenic differentiation medium. The osteogenic differentiation medium was composed of rMSC osteogenic differentiation basal medium with FBS, glutamine, penicillin-streptomycin, ascorbate, $\beta$-glycerophosphate, and dexamethasone (Cyagen Biosciences). The mineralizing medium or osteogenic differentiation medium was changed every 3 days.

\section{Cell attachment and cytoskeletal organization}

rMSCs were seeded on samples at a cell density of $5 \times$ $10^{5}$ cells $/ \mathrm{mL}$ and allowed to attach for 3 hours in serum-free growth medium. After 3 hours' incubation, cells were washed twice with PBS and lysed using a buffer containing $0.5 \%$ Triton $^{\mathrm{TM}} \mathrm{X}-100$. The total double-stranded DNA (dsDNA) in the lysate was measured using the quant-iT ${ }^{\mathrm{TM}}$ PicoGreen
dsDNA Reagent and Kits (Thermo Fisher Scientific, Waltham, MA, USA) according to the manufacturer's protocol. The fluorescence at wavelengths of 480/520 nm was determined using a fluorescence microplate reader (FLUOstar OPTIMA; Moritex Bio Science, Tokyo, Japan) and DNA quantity was determined by using standard DNA dilution series.

For actin staining, rMSCs were washed gently with PBS, then fixed using a solution of $10 \%$ neutral buffered formalin for 10 minutes at room temperature. The cells were permeabilized using $0.5 \%$ Triton $\mathrm{X}-100$ in PBS for 5 minutes, then again washed with PBS. The rMSCs were incubated with rhodamineconjugated phalloidin (1:139 dilution in PBS; Thermo Fisher Scientific) for 30 minutes in the dark followed by counterstaining with 4',6-diamidino-2-phenylindole (DAPI) (Sigma-Aldrich Co.) to visualize the nuclei. Images were taken at $20 \times$ magnification with a confocal microscope (MRC-1024 MP; Bio-Rad Laboratories Inc., Hercules, CA, USA) in random fields.

\section{Cell proliferation}

rMSC proliferation was quantitatively assessed using Cell Counting Kit-8 (CCK-8; Beyotime, Shanghai, People's Republic of China). rMSCs were seeded on samples at a density of $1 \times 10^{4}$ cells $/ \mathrm{mL}$ in growth medium for $1,3,5$, and 7 days. At determined time intervals, samples were rinsed with PBS, then $250 \mu \mathrm{L}$ of fresh growth medium with $25 \mu \mathrm{L}$ of CCK-8 reagents were added to each sample. The cell culture plates were incubated under the same cultivation conditions for another hour, then reagents were carefully transferred to 96-well plates. The absorbance was measured using a microplate reader (ELx808; BioTek Instrusments, Vermont, USA) at $450 \mathrm{~nm}$.

\section{ALP activity assay}

The ALP activity of osteogenic differentiation-induced rMSCs on each sample was determined using LabAssay ${ }^{\text {TM }}$ ALP (Wako Pure Chemical Industries, Ltd., Osaka, Japan). rMSCs were seeded at a density of $4 \times 10^{4}$ cells $/ \mathrm{mL}$ on samples. At determined time intervals, samples were washed gently and lysed in extraction solution (Takara Biomedicals, Otsu, Japan). The lysate was added to working assay solution in 96 -well plates and incubated for 15 minutes at $37^{\circ} \mathrm{C}$. The reaction was stopped using $0.2 \mathrm{M} \mathrm{NaOH}$. The absorbance was measured at $405 \mathrm{~nm}$ using a microplate reader. ALP activity was calculated from a standard curve after normalizing to the total protein content, which was measured using the Micro BCA Protein Assay Kit. ALP activity was expressed as nmol of p-nitrophenol formation $/ \mathrm{min} / \mathrm{mg}$ of total proteins. ALP activity was determined at day 3,7 , and 14 . 


\section{OC production}

rMSCs were seeded at a density of $4 \times 10^{4}$ cells $/ \mathrm{mL}$ on samples for 7, 14, and 21 days. At the predetermined time intervals, the supernatant of the culture medium was collected from all wells and centrifuged to remove particulates. Aliquots were dispensed in Eppendorf tubes for storage at $-80^{\circ} \mathrm{C}$ and measured using an OC enzyme-linked immunosorbent assay kit (USCN Life Science Inc., Wuhan, People's Republic of China) according to the manufacturer's protocol. Aliquots were thawed and placed into the precoated 96-well plate. A standard curve ranging from 0 to $50 \mathrm{ng} / \mathrm{mL}$ was prepared. After reaction termination, the absorbance was immediately measured at $450 \mathrm{~nm}$ using a microplate reader.

\section{Calcium deposition}

To quantify the extent of mineralization, rMSCs were seeded at a density of $1 \times 10^{4}$ cells $/ \mathrm{mL}$ on samples for 28 days. At the end of the experimental period, rMSCs were washed with PBS and lysed in RIPA lysis buffer (Beyotime). The resulting supernatant was used for calcium deposition measurement using a commercial calcium assay kit (DICA-500; BioAssay Systems, Hayward, CA, USA). Briefly, the calciumcontaining supernatant was mixed with the working reagent, then the mixture was incubated for 3 minutes. The absorbance was measured at $612 \mathrm{~nm}$ using a microplate reader. Total deposited calcium was calculated from a standard curve.

\section{Statistical analysis}

Analysis of variance (ANOVA) was performed on data sets when appropriate using a significance of $P$-values $<0.05$. Separate one-way analyses of variance were used to analyze cell attachment, cell proliferation, ALP activity, OC production, and calcium deposition. The Student-Newman-Keuls post hoc comparison test was used for pairwise comparisons.

\section{Results \\ Effects of loading methods on surface characteristics}

A porous network structure was formed by alkali treatment (Figure 2A), which facilitated nucleation and the
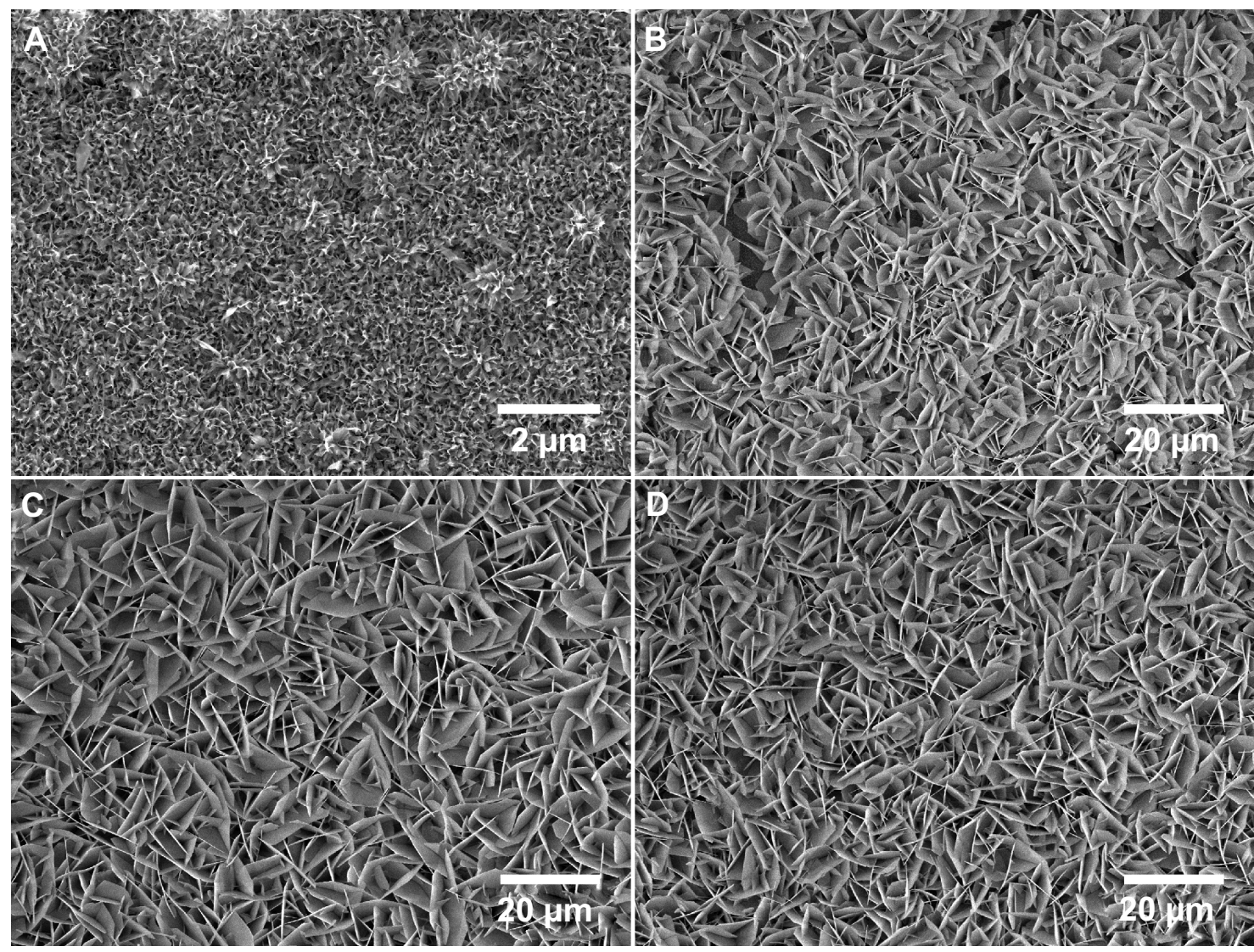

Figure 2 Scanning electron microscope images of representative samples.

Notes: Samples from each of the following groups were examined: alkali-treated titanium substrate (A), 24-hour mineralization (B); 24-hour mineralization, 24-hour coprecipitation of mineral and OGP (C); 24-hour mineralization, OGP adsorption (D).

Abbreviation: OGP, osteogenic growth peptide. 
growth of a layer of mineral. A cavernous, uniform layer composed of very fine flake mineral crystallites was apparent on the surface of the mineralization control (Figure 2B). The flakes of mineral with coprecipitated OGP (Figure 2C) seemed to be slightly larger than those of the control samples, whereas the adsorption of OGP (Figure 2D) did not change the morphology of the flakes. Through comparisons with Joint Committee on Powder Diffraction Standards (JCPDS) standard cards, the mineral layer formed on alkali-treated $\mathrm{Ti}$ was indexed as a mixture of low-crystalline apatite and octacalcium phosphate (OCP) (Figure 3). In the coprecipitation scheme, an OCP layer incorporated with OGP was grown on the mineralized substrates, and the newly formed layer was observed to have a very pronounced preferential crystallographic direction of 002. No additional crystalline phase was observed after adsorption of OGP.

\section{Effects of loading methods on the release of OGP}

The amount of coprecipitated or adsorbed FITC-OGP was approximately $5 \mu \mathrm{g}$ per sample. The release behaviors of FITC-OGP from prepared substrates are depicted in Figure 4. In general, the OGP release for both loading methods followed biphasic release kinetics. The $\mathrm{cO}$ group released approximately $58.74 \% \pm 4.10 \%$ of the FITC-OGP during the initial 24 hours, after which the release rate leveled off. Over a period of 15 days, $68.82 \% \pm 4.84 \%$ of the FITC-OGP was released from the coprecipitated surfaces. The amount of FITC-OGP released from the aO group on the first day

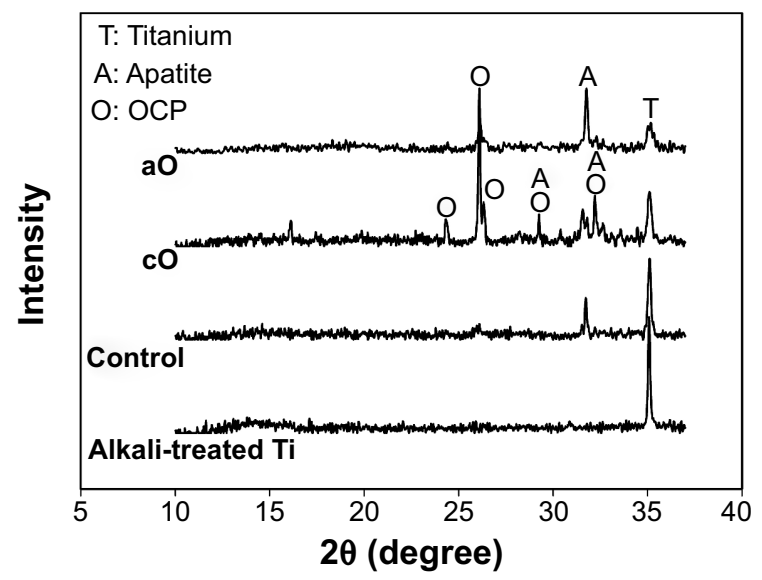

Figure 3 XRD patterns of representative samples.

Notes: Samples from each of the following groups were examined: alkali-treated titanium substrate (Alkali-treated Ti); 24-hour mineralization (Control); 24hour mineralization, 24-hour coprecipitation of mineral and OGP (cO); 24-hour mineralization, OGP adsorption (aO).

Abbreviations: XRD, X-ray diffraction; OGP, osteogenic growth peptide; $A$, apatite; $\mathrm{O}$, octacalcium phosphate; $\mathrm{T}$, titanium. was approximately $62.88 \% \pm 5.28 \%$, which was followed by a more gradual and steady release, at $1.5 \%$ /day up to 15 days, totaling $84.49 \% \pm 8.13 \%$.

\section{Effects of OGP and FN on cell attachment and morphology}

The initial attachment of MSCs to the surface of the biomaterials is a crucial early step in osseointegration. ${ }^{23}$ The cells were cultured in serum-free conditions to measure the direct effects of loaded BMs on cell attachment. rMSC attachment on prepared substrates was determined with the PicoGreen ${ }^{\circledR}$ dsDNA assay. As shown in Figure 5, groups that were loaded with BMs had higher DNA levels than the mineralization control $(P<0.05)$. DNA quantity was higher with aF as compared with both $\mathrm{cO}$ and $\mathrm{aO}(P<0.05)$, with no significant difference between $\mathrm{cO}$ and aO $(P>0.05)$. The sample with $\mathrm{cO} / \mathrm{aF}$ demonstrated greater $\mathrm{rMSC}$ attachment than samples with $\mathrm{cO}$ and $\mathrm{aO}(P<0.05)$, but there was no statistical significance compared with aF $(P>0.05)$. rMSC attachment with aOF was found to be the highest among all prepared substrates.

Figure 6 shows the morphology of cells attached to the prepared substrates by labeling of the actin cytoskeleton with rhodamine-conjugated phalloidin. Consistent with the attachment assays, few cells were bound to mineralization control, and the cells retained a rounded morphology (Control; Figure 6). Although more cells had adhered to OGP-loaded samples, their shape was very rounded ( $\mathrm{cO}$ and $\mathrm{aO}$; Figure 6). In contrast, rMSCs were able to spread on samples loaded with FN alone or OGP and FN together (aF, cO/aF, and aOF; Figure 6),

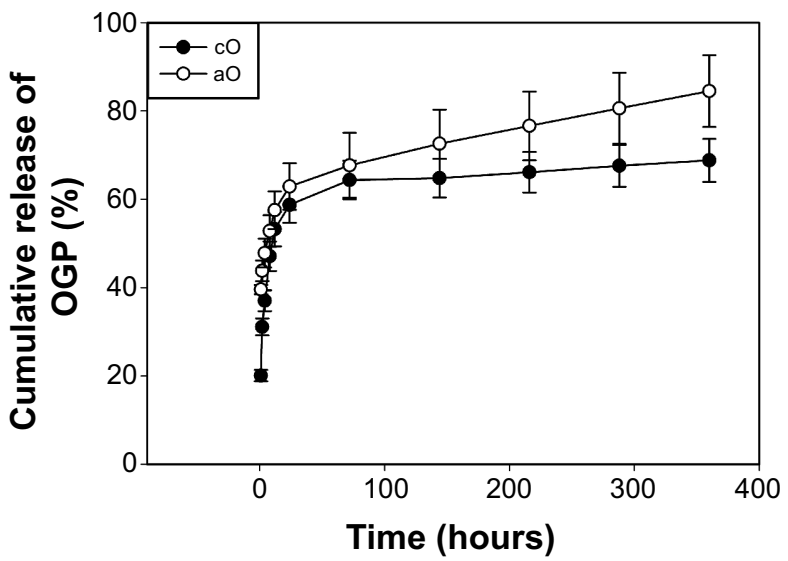

Figure 4 In vitro cumulative release of FITC-OGP in PBS over the 14-day time period.

Notes: Samples were prepared via 24-hour mineralization, 24-hour coprecipitation of mineral and FITC-OGP (cO) and 24-hour mineralization, FITC-OGP adsorption $(\mathrm{aO})$. The values represent the mean \pm standard deviation $(n=3)$.

Abbreviations: FITC-OGP, fluorescein isothiocyanate-labeled OGP; OGP, osteogenic growth peptide; PBS, phosphate-buffered saline. 


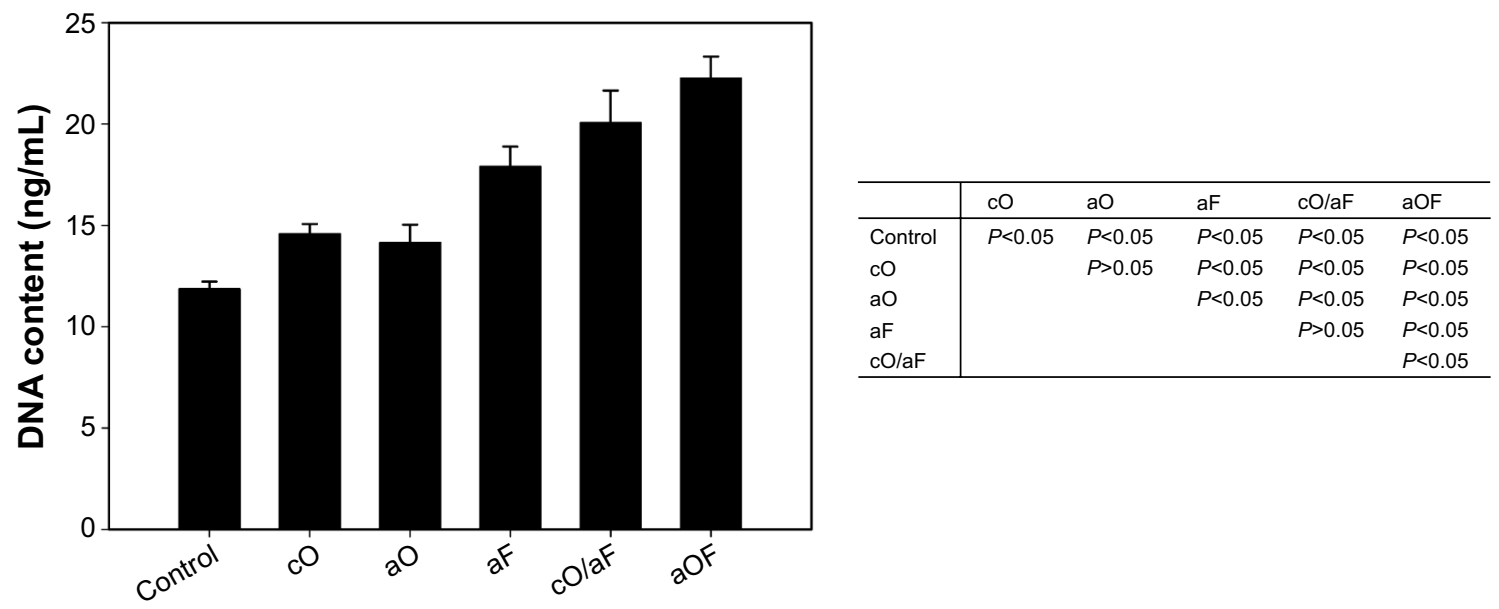

Figure 5 Total DNA quantified of rMSCs adhered to the representative samples in serum-free growth medium for 3 hours.

Notes: The samples were prepared as follows: 24-hour mineralization (Control); 24-hour mineralization, 24-hour coprecipitation of mineral and OGP (cO); 24-hour mineralization, OGP adsorption (aO); 24-hour mineralization, FN adsorption (aF); 24-hour mineralization, 24-hour coprecipitation of mineral and OGP, FN adsorption (cO/ $\mathrm{aF})$; 24-hour mineralization, OGP and FN adsorption (aOF). The values represent the mean \pm standard deviation ( $\mathrm{n}=4$ or 5 ). In the table, pairwise comparisons of each of the groups were performed using the Student-Newman-Keuls post hoc comparison test, and significance is $P<0.05$.

Abbreviations: OGP, osteogenic growth peptide; FN, fibronectin; rMSCs, rat mesenchymal stem cells.

and cells exhibited substantial actin polymerization, in the form of lamellipodia, pseudopodia, and actin stress fibers.

\section{Effects of OGP and FN on cell proliferation}

The effects of loaded OGP and FN on the proliferative activity of rMSCs were investigated at day 1, 3, 5, and 7 using CCK-8 assay (Figure 7). For the $\mathrm{cO}, \mathrm{aO}, \mathrm{cO} / \mathrm{aF}$, and
aOF samples, cell proliferation continuously increased up to the fifth day and then exhibited relatively unchanged proliferation, likely due to the cells' confluence, whereas, with $\mathrm{aF}$ and mineralization control, the proliferation increased throughout the incubation period of 7 days.

The samples with $\mathrm{cO}, \mathrm{aO}, \mathrm{cO} / \mathrm{aF}$, and $\mathrm{aOF}$ had a significant positive effect on rMSC proliferation compared with the mineralization control $(P<0.05)$. No significant differences
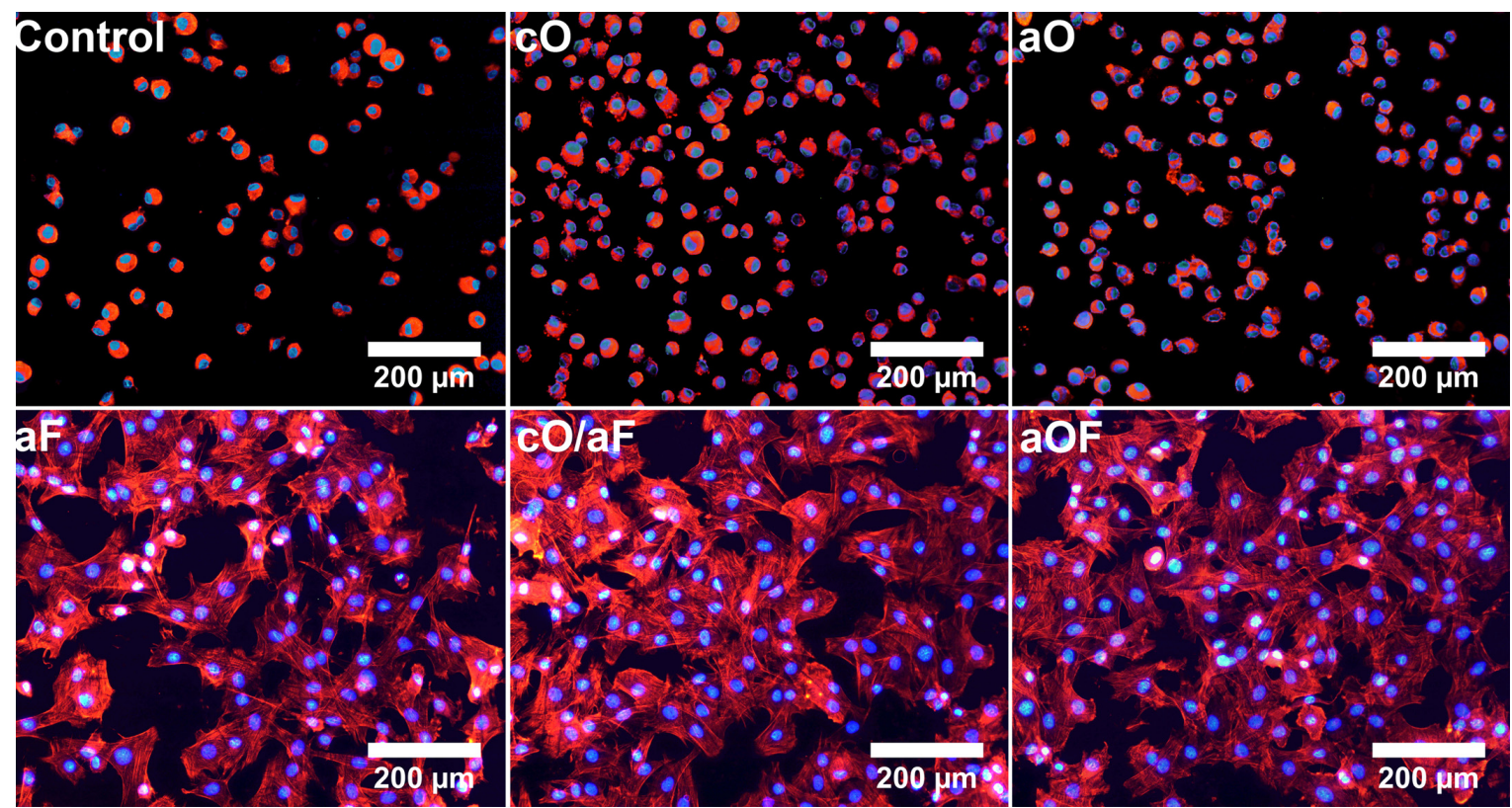

Figure 6 Confocal microscope images of rMSCs cultured on the representative samples in serum-free growth medium for 3 hours.

Notes: The samples were prepared as follows: 24-hour mineralization (Control); 24-hour mineralization, 24-hour coprecipitation of mineral and OGP (cO); 24-hour mineralization, OGP adsorption (aO); 24-hour mineralization, FN adsorption (aF); 24-hour mineralization, 24-hour coprecipitation of mineral and OGP, FN adsorption (cO/ aF); 24-hour mineralization, OGP and FN adsorption (aOF). DAPI stained the nuclei (blue), and rhodamine phalloidin stained the cytoskeleton (red).

Abbreviations: DAPI, 4',6-diamidino-2-phenylindole; OGP, osteogenic growth peptide; FN, fibronectin; rMSCs, rat mesenchymal stem cells. 


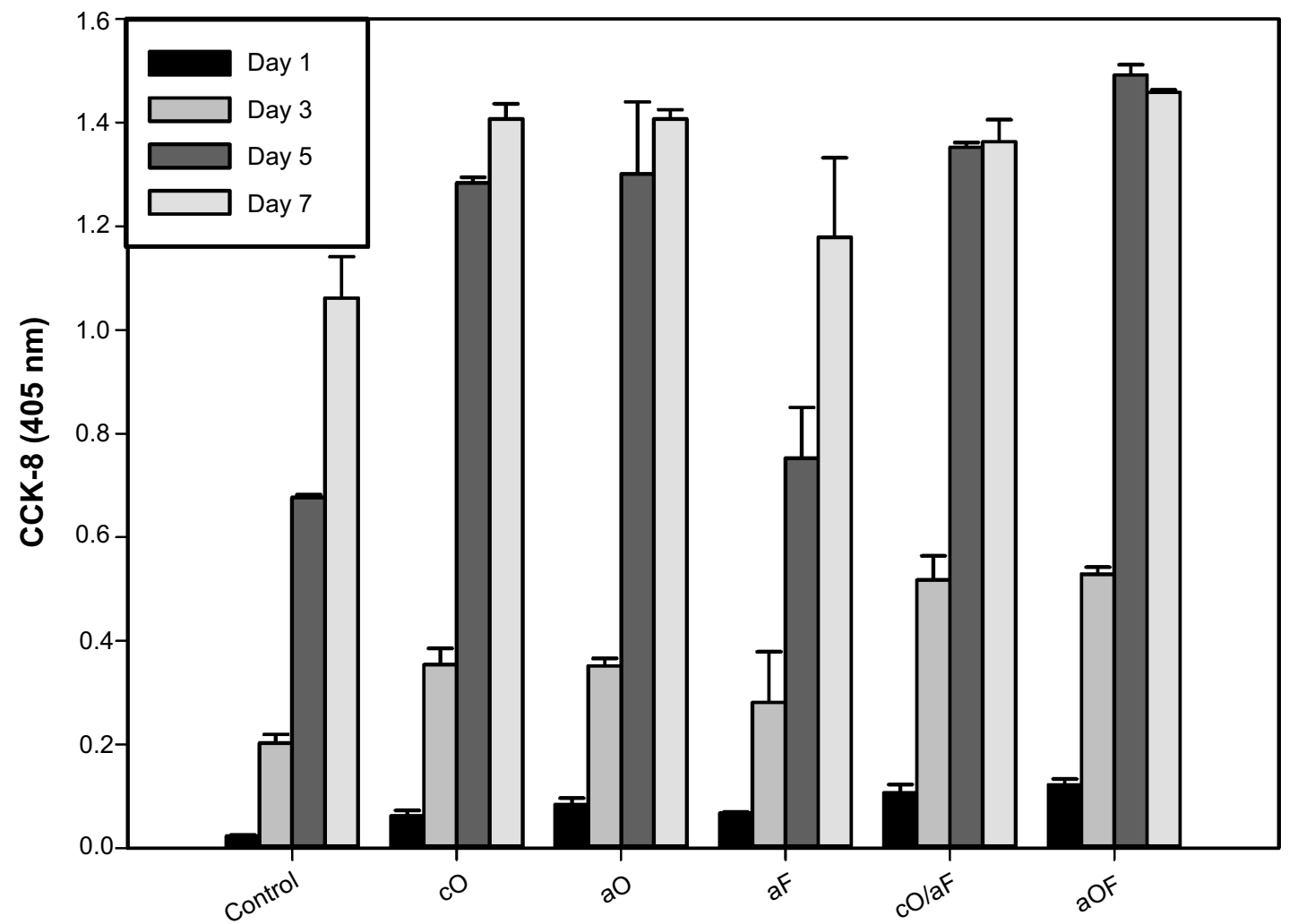

\begin{tabular}{l|lllll}
\hline Day 1 & $\mathrm{cO}$ & $\mathrm{aO}$ & $\mathrm{aF}$ & $\mathrm{cO} / \mathrm{aF}$ & $\mathrm{aOF}$ \\
\hline Control & $P<0.05$ & $P<0.05$ & $P<0.05$ & $P<0.05$ & $P<0.05$ \\
$\mathrm{cO}$ & & $P>0.05$ & $P>0.05$ & $P<0.05$ & $P<0.05$ \\
$\mathrm{aO}$ & & & $P>0.05$ & $P<0.05$ & $P<0.05$ \\
$\mathrm{aF}$ & & & & $P<0.05$ & $P<0.05$ \\
$\mathrm{cO} / \mathrm{aF}$ & & & & & $P>0.05$ \\
\hline Day 5 & $\mathrm{cO}$ & $\mathrm{aO}$ & $\mathrm{aF}$ & $\mathrm{cO} / \mathrm{aF}$ & $\mathrm{aOF}$ \\
\hline Control & $P<0.05$ & $P<0.05$ & $P>0.05$ & $P<0.05$ & $P<0.05$ \\
$\mathrm{cO}$ & & $P>0.05$ & $P<0.05$ & $P>0.05$ & $P<0.05$ \\
aO & & & $P<0.05$ & $P>0.05$ & $P<0.05$ \\
aF & & & & $P<0.05$ & $P<0.05$ \\
cO/aF & & & & & $P<0.05$ \\
\hline
\end{tabular}

\begin{tabular}{l|lllll}
\hline Day 3 & $\mathrm{cO}$ & $\mathrm{aO}$ & $\mathrm{aF}$ & $\mathrm{cO} / \mathrm{aF}$ & $\mathrm{aOF}$ \\
\hline Control & $P<0.05$ & $P<0.05$ & $P>0.05$ & $P<0.05$ & $P<0.05$ \\
$\mathrm{cO}$ & & $P>0.05$ & $P>0.05$ & $P<0.05$ & $P<0.05$ \\
$\mathrm{aO}$ & & & $P>0.05$ & $P<0.05$ & $P<0.05$ \\
$\mathrm{aF}$ & & & & $P<0.05$ & $P<0.05$ \\
$\mathrm{cO} / \mathrm{aF}$ & & & & & $P>0.05$ \\
\hline Day 7 & $\mathrm{cO}$ & $\mathrm{aO}$ & $\mathrm{aF}$ & $\mathrm{cO} / \mathrm{aF}$ & $\mathrm{aOF}$ \\
\hline Control & $P<0.05$ & $P<0.05$ & $P>0.05$ & $P<0.05$ & $P<0.05$ \\
$\mathrm{cO}$ & & $P>0.05$ & $P<0.05$ & $P>0.05$ & $P>0.05$ \\
$\mathrm{aO}$ & & & $P<0.05$ & $P>0.05$ & $P>0.05$ \\
$\mathrm{aF}$ & & & & $P<0.05$ & $P<0.05$ \\
$\mathrm{cO} / \mathrm{aF}$ & & & & & $P>0.05$ \\
\hline
\end{tabular}

Figure 7 Cell proliferation of rMSCs cultured on the representative samples in growth medium for I, 3, 5, and 7 days.

Notes: The samples were prepared as follows: 24-hour mineralization (Control); 24-hour mineralization, 24-hour coprecipitation of mineral and OGP (cO); 24-hour mineralization, OGP adsorption (aO); 24-hour mineralization, FN adsorption (aF); 24-hour mineralization, 24-hour coprecipitation of mineral and OGP, FN adsorption (cO/ aF); 24-hour mineralization, OGP and FN adsorption (aOF). The values represent the mean \pm standard deviation ( $n=4$ or 5 ). In the table, pairwise comparisons of each of the groups were performed using the Student-Newman-Keuls post hoc comparison test, and significance is $P<0.05$.

Abbreviations: CCK-8, Cell Counting Kit-8; OGP, osteogenic growth peptide; FN, fibronectin; rMSCs, rat mesenchymal stem cells.

were noted in the proliferation levels of rMSCs with $\mathrm{cO}$ compared with aO $(P>0.05)$. The $\mathrm{cO} / \mathrm{aF}$ and aOF samples showed significantly higher proliferation values compared with aF $(P<0.05)$.

At day 1 and day 3 , there was no significant difference in rMSC proliferation on singly loaded $\mathrm{FN}(\mathrm{aF})$ and OGP (cO and $\mathrm{aO})(P>0.05)$. In dually loaded samples $(\mathrm{cO} / \mathrm{aF}$ and $\mathrm{aOF})$, proliferation levels were higher than with $\mathrm{cO}$ and $\mathrm{aO}(P<0.05)$, with no statistical difference between $\mathrm{cO} /$ $\mathrm{aF}$ and aOF $(P>0.05)$. At day $5, \mathrm{aF}$ showed a significantly lower proliferation value when compared with $\mathrm{cO}$ and $\mathrm{aO}$
$(P<0.05)$. The aOF sample had a significantly higher proliferation level than $\mathrm{cO}, \mathrm{aO}$, and $\mathrm{cO} / \mathrm{aF}(P<0.05)$, while proliferation was higher with $\mathrm{cO} / \mathrm{aF}$ compared with $\mathrm{cO}$ and aO, but with no statistical difference $(P>0.05)$. At day $7, \mathrm{aF}$ had a lower proliferation value when compared with $\mathrm{cO}$ and $\mathrm{aO}(P<0.05)$. There was no statistical difference between samples with singly loaded OGP $(\mathrm{cO}$ and $\mathrm{aO})$ and those with dually loaded ones $(\mathrm{cO} / \mathrm{aF}$, aOF $)(P>0.05)$. Furthermore, the different methods of loading OGP in the $\mathrm{cO} / \mathrm{aF}$ and aOF samples did not show any obvious effect on rMSC proliferation $(P>0.05)$. 


\section{Effects of OGP and FN on ALP activity}

To investigate the tendency of rMSCs to differentiate into osteoblasts, rMSCs were seeded on each sample in mineralizing medium. For the positive control, rMSCs were cultured on mineralization control in osteogenic differentiation medium. ALP is one of the markers of early differentiation, which is attributed to the mineralization of skeletal tissues. ${ }^{24}$

The ALP activities of rMSCs were determined at day 3, 7, and 14 (Figure 8). With longer incubation periods, the ALP activities of both mineralization control and aF continuously increased, while, in the positive control and the samples with $\mathrm{cO}, \mathrm{aO}, \mathrm{cO} / \mathrm{aF}$, and $\mathrm{aOF}$, the ALP activity increased, reaching its maximum at 7 days, then slightly decreased at 14 days. The samples with $\mathrm{cO}, \mathrm{aO}, \mathrm{cO} / \mathrm{aF}$, and $\mathrm{aOF}$ had higher ALP activity than the mineralization control $(P<0.05)$. The aOF samples had a significant positive effect compared with $\mathrm{aF}, \mathrm{cO}$, and $\mathrm{aO}(P<0.05)$. The ALP activity with different methods of loading OGP alone (cO versus aO) was not statistically different. However, there was significantly higher ALP activity with aOF than with $\mathrm{cO} / \mathrm{aF}(P<0.05)$, and the ALP activity with aOF was even higher than the positive control.

At day 3 and day 7, although not statistically significant, $\mathrm{cO}$ and $\mathrm{aO}$ resulted in higher ALP activity compared with
$\mathrm{aF}(P>0.05)$. ALP activity with $\mathrm{cO} / \mathrm{aF}$ was slightly higher than that found with $\mathrm{aF}, \mathrm{cO}$, and $\mathrm{aO}(P>0.05)$. At day 14, there was no statistical difference among $\mathrm{aF}, \mathrm{cO}, \mathrm{aO}$, and $\mathrm{cO} / \mathrm{aF}(P>0.05)$.

\section{Effects of OGP and FN in the late stage of osteogenic differentiation}

OC secretion and calcium deposition by rMSCs are markers that indicate the late stage of osteogenic differentiation. ${ }^{25} \mathrm{An}$ OC enzyme-linked immunosorbent assay kit was employed to determine the production of $\mathrm{OC}$ at day 7,14 , and 21 (Figure 9). For all determined points, the addition of BMs had significant effects on OC secretion compared with mineralization control $(P<0.05)$. The samples with $\mathrm{cO}$ and $\mathrm{aO}$ led to higher levels of OC compared to aF $(P<0.05)$. Positive control, $\mathrm{cO} / \mathrm{aF}$, and aOF resulted in higher OC expression than $\mathrm{aF}, \mathrm{cO}$, and $\mathrm{aO}(P<0.05)$. The OC secretion with $\mathrm{cO} / \mathrm{aF}$ was slightly lower than that with the positive control, while aOF presented comparable (at day 21) or higher (at day 7 and day 14) OC values compared with positive control. The different methods of loading OGP with or without adsorbed FN had some effects on OC secretion. rMSCs seeded on samples with $\mathrm{cO}$ secreted less $\mathrm{OC}$ than those with aO $(P<0.05)$.

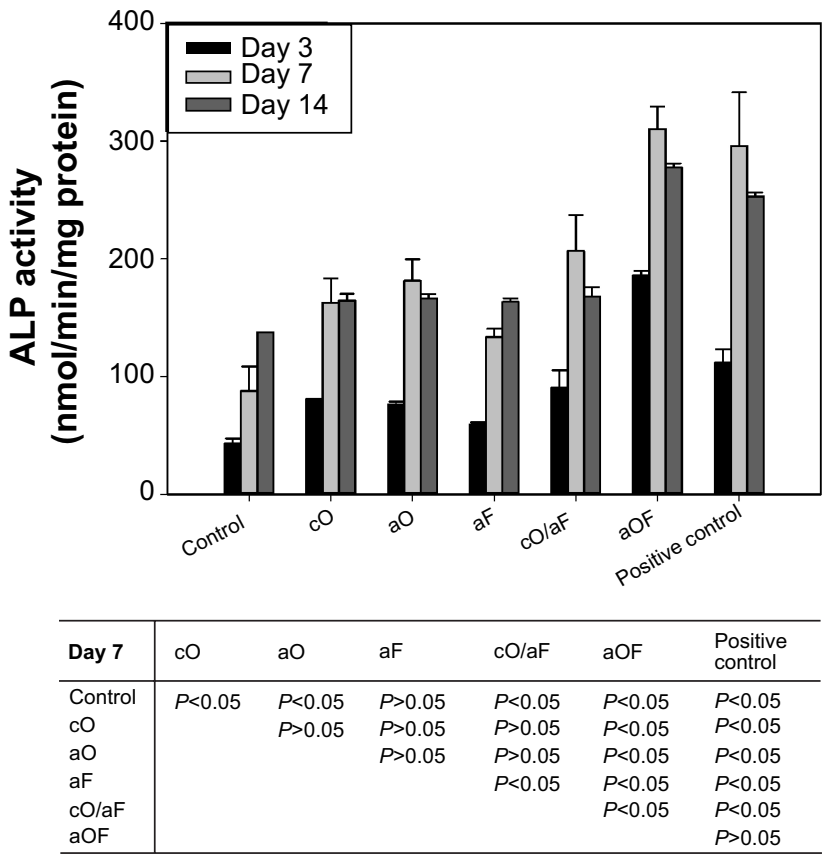

\begin{tabular}{l|llllll}
\hline Day 3 & cO & aO & aF & cO/aF & aOF & $\begin{array}{l}\text { Positive } \\
\text { control }\end{array}$ \\
\hline Control & $P<0.05$ & $P<0.05$ & $P>0.05$ & $P<0.05$ & $P<0.05$ & $P<0.05$ \\
cO & & $P>0.05$ & $P>0.05$ & $P>0.05$ & $P<0.05$ & $P>0.05$ \\
aO & & & $P>0.05$ & $P>0.05$ & $P<0.05$ & $P>0.05$ \\
aF & & & & $P>0.05$ & $P<0.05$ & $P<0.05$ \\
cO/aF & & & & & $P<0.05$ & $P>0.05$ \\
aOF & & & & & & $P<0.05$ \\
\hline
\end{tabular}

Figure 8 Normalized ALP activities with respect to total protein of rMSCs cultured on the representative samples for 3, 7, and I4 days.

Notes: rMSCs were cultured on samples in mineralizing medium as follows: 24-hour mineralization (Control); 24-hour mineralization, 24-hour coprecipitation of mineral and OGP (cO); 24-hour mineralization, OGP adsorption (aO); 24-hour mineralization, FN adsorption (aF); 24-hour mineralization, 24-hour coprecipitation of mineral and OGP, $\mathrm{FN}$ adsorption (cO/aF); 24-hour mineralization, OGP and FN adsorption (aOF); or rMSCs were cultured on 24-hour mineralization samples in osteogenic differentiation medium (Positive control). The values represent the mean \pm standard deviation ( $n=4$ or 5$)$. In the table, pairwise comparisons of each of the groups were performed using the Student-Newman-Keuls post hoc comparison test, and significance is $P<0.05$.

Abbreviations: ALP, alkaline phosphatase; OGP, osteogenic growth peptide; FN, fibronectin; rMSCs, rat mesenchymal stem cells. 


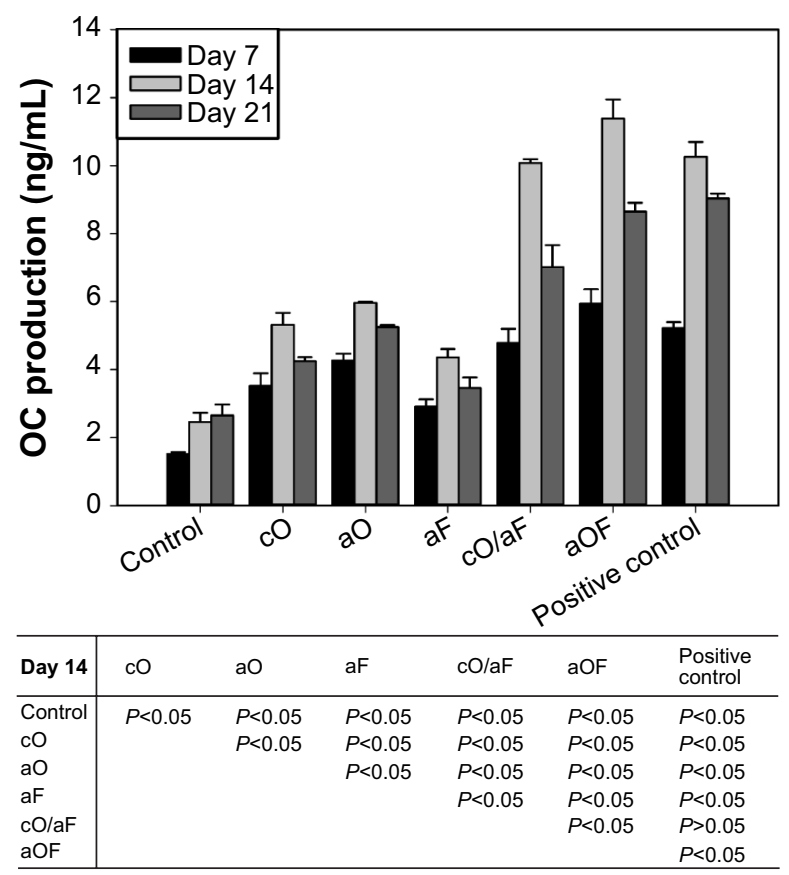

\begin{tabular}{l|llllll}
\hline Day 7 & cO & aO & aF & cO/aF & aOF & $\begin{array}{l}\text { Positive } \\
\text { control }\end{array}$ \\
\hline Control & $P<0.05$ & $P<0.05$ & $P<0.05$ & $P<0.05$ & $P<0.05$ & $P<0.05$ \\
cO & & $P<0.05$ & $P<0.05$ & $P<0.05$ & $P<0.05$ & $P<0.05$ \\
aO & & & $P<0.05$ & $P<0.05$ & $P<0.05$ & $P<0.05$ \\
aF & & & & $P<0.05$ & $P<0.05$ & $P<0.05$ \\
cO/aF & & & & & $P<0.05$ & $P>0.05$ \\
aOF & & & & & & $P<0.05$ \\
\hline
\end{tabular}

Figure 9 OC production of rMSCs cultured on the representative samples for 7,14 , and 21 days.

Notes: $r$ MSCs were cultured on samples in mineralizing medium as follows: 24-hour mineralization (Control); 24-hour mineralization, 24-hour coprecipitation of mineral and OGP (cO); 24-hour mineralization, OGP adsorption (aO); 24-hour mineralization, FN adsorption (aF); 24-hour mineralization, 24-hour coprecipitation of mineral and OGP, FN adsorption (cO/aF); 24-hour mineralization, OGP and FN adsorption (aOF); or rMSCs were cultured on 24-hour mineralization samples in osteogenic differentiation medium (Positive control). The values represent the mean \pm standard deviation $(n=4$ or 5$)$. In the table, pairwise comparisons of each of the groups were performed using the Student-Newman-Keuls post hoc comparison test, and significance is $P<0.05$.

Abbreviations: OC, osteocalcin; OGP, osteogenic growth peptide; FN, fibronectin; rMSCs, rat mesenchymal stem cells.

Furthermore, OC expression was significantly higher for samples with aOF when compared with that with $\mathrm{cO} / \mathrm{aF}$ $(P<0.05)$. By day 21, the OC secretion had not increased, and had even shown a slight reduction compared to day 14 , with regard to both the control and experimental groups.
Calcium deposition after culturing rMSCs for 28 days on prepared substrates is shown in Figure 10. Cells adherent to mineralization control resulted in the lowest calcium deposition. The samples with $\mathrm{cO}$ and $\mathrm{aO}$ consistently demonstrated higher calcium deposition compared with aF $(P<0.05)$. The

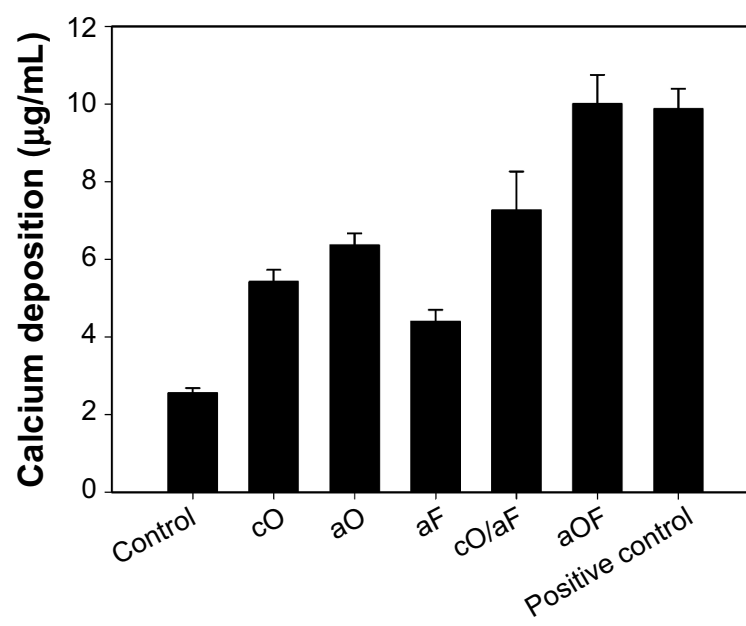

\begin{tabular}{l|llllll}
\hline & $\mathrm{cO}$ & $\mathrm{aO}$ & $\mathrm{aF}$ & $\mathrm{cO} / \mathrm{aF}$ & $\mathrm{aOF}$ & $\begin{array}{l}\text { Positive } \\
\text { control }\end{array}$ \\
\hline Control & $P<0.05$ & $P<0.05$ & $P<0.05$ & $P<0.05$ & $P<0.05$ & $P<0.05$ \\
$\mathrm{cO}$ & & $P>0.05$ & $P<0.05$ & $P<0.05$ & $P<0.05$ & $P<0.05$ \\
$\mathrm{aO}$ & & & $P<0.05$ & $P>0.05$ & $P<0.05$ & $P<0.05$ \\
$\mathrm{aF}$ & & & & $P<0.05$ & $P<0.05$ & $P<0.05$ \\
$\mathrm{cO} / \mathrm{aF}$ & & & & & $P<0.05$ & $P<0.05$ \\
$\mathrm{aOF}$ & & & & & & $P>0.05$ \\
\hline
\end{tabular}

Figure 10 The calcium deposition content of rMSCs cultured on the representative samples for 28 days.

Notes: rMSCs were cultured on samples in mineralizing medium as follows: 24-hour mineralization (Control); 24-hour mineralization, 24-hour coprecipitation of mineral and OGP (cO); 24-hour mineralization, OGP adsorption (aO); 24-hour mineralization, FN adsorption (aF); 24-hour mineralization, 24-hour coprecipitation of mineral and OGP, FN adsorption (cO/aF); 24-hour mineralization, OGP and FN adsorption (aOF); or rMSCs were cultured on 24-hour mineralization samples in osteogenic differentiation medium (Positive control). The values represent the mean \pm standard deviation ( $n=4$ or 5 ). In the table, pairwise comparisons of each of the groups were performed using the Student-Newman-Keuls post hoc comparison test, and significance is $P<0.05$.

Abbreviations: OGP, osteogenic growth peptide; FN, fibronectin; rMSCs, rat mesenchymal stem cells. 
positive control and aOF resulted in the highest calcium deposition following a similar trend in $\mathrm{OC}$ secretion. $\mathrm{cO} / \mathrm{aF}$ had a more positive effect on calcium deposition than $\mathrm{aF}$, $\mathrm{cO}$, and $\mathrm{aO}$. The calcium deposition with $\mathrm{cO} / \mathrm{aF}$ compared to that with $\mathrm{aF}$ and $\mathrm{cO}$ was significantly different $(P<0.05)$, but there was no statistical difference between $\mathrm{cO} / \mathrm{aF}$ with aO $(P>0.05)$. Although not statistically significant, $\mathrm{cO}$ resulted in lower calcium deposition compared with aO $(P>0.05)$; however, aOF had significantly higher deposition compared with $\mathrm{cO} / \mathrm{aF}(P<0.05)$.

\section{Discussion}

The aim of this study was to investigate titanium surfaces immobilized with OGP and FN to achieve optimally osteogenic-differentiating rMSCs. Adsorption and coprecipitation methods of loading BMs were chosen. The release profiles, physicochemical characteristics, and effects of the two different methods of loading OGP with and without adsorbed FN on rMSCs were evaluated.

In our previous study, FN retained its biological activity in terms of promoting osteocyte adhesion and spreading when $7.55 \mu \mathrm{g}$ FN was immobilized with apatite. ${ }^{10}$ OGP had a significant positive effect on both proliferation and osteogenic differentiation at the loaded amount of $5 \mu \mathrm{g}$ in our preliminary experiment (data not shown). DPBS containing $20 \mu \mathrm{g} / \mathrm{mL}$ of OGP was chosen to immobilize $5 \mu \mathrm{g}$ OGP for the coprecipitation procedure, while, for adsorption, distilled water containing $250 \mu \mathrm{g} / \mathrm{mL}$ of OGP or $400 \mu \mathrm{g} / \mathrm{mL}$ of FN was chosen to load $5 \mu \mathrm{g}$ of OGP or $8 \mu \mathrm{g}$ of FN, respectively.

The first objective of this study was to investigate the effects of different loading methods on release profiles. An initial burst release pattern of OGP was observed in both the coprecipitation and adsorption groups, but the adsorbed OGP showed more gradual and sustained release after the initial burst (Figure 4). The release of coprecipitated BMs from the mineral layer is mainly dependent on the dissolution of the mineral layer and the diffusion of BMs in the mineral layer. ${ }^{26}$ In our previous study, the mineral was composed of two sublayers, ie, a loose OCP crystal top layer and a dense apatite crystal bottom layer. ${ }^{5}$ The top OCP layer can gradually dissolve under physiological conditions, ${ }^{27}$ while the bottom apatite layer hardly degrades. ${ }^{28}$ In the present study, as OCP was more grown onto the preformed mineral layer during coprecipitation (Figure 3), and some of the OGP was superficially adsorbed onto the outmost surface, an initial bursting release was observed due to desorption of superficial adsorbed OGP, followed by gradual release via the dissolution of the top OCP mineral layer. Similar results were reported by Yu et al. ${ }^{29}$ For the adsorbed OGP, sustained release of FITC-OGP after initial burst may be explained by the electrostatic interaction between positively charged OGP (isoelectric point $=11.4$ ) and negatively charged adsorption sites of mineral. ${ }^{15}$ This may also be due to the high surface area of the cavernous and flake-like morphology of biomimetically formed mineral offering more binding sites for nonspecific BM adsorption.

We hypothesized that different release profiles would influence the osteogenic differentiation of MSCs, and that the cell adhesion molecule FN would further improve the osteogenic efficiency when it was immobilized together with OGP on titanium surfaces. The factors, which were found to affect the level of rMSC proliferation and osteogenic differentiation, were summarized in Table 2.

Differences in the loading methods of OGP alone had little impact on the proliferation and osteogenic differentiation of the rMSCs. When compared with coprecipitated OGP, the adsorbed OGP could lead to higher OC secretion and matrix mineralization (Figures 9 and 10), but with no change in cell growth or early osteogenic differentiation (Figures 7 and 8). In the literature, it is shown that OGP stimulates the osteogenic differentiation in a dose-dependent way. ${ }^{30-32}$ As the release of adsorbed OGP was more sustained than that of the coprecipitated OGP (as shown in Figure 4), the doses of released peptides from adsorbed OGP alone are higher than those from coprecipitated OGP alone at the late stage of differentiation, which might be more optimal for rMSC secretion of OC and extracellular matrix depositing.

Dually loaded OGP and FN had positive effects on rMSC growth and osteogenic differentiation. The simultaneously adsorbed OGP and FN resulted in a significant increase in rMSC proliferation and differentiation compared with individually loaded OGP or FN (Figures 7-10). When compared with individually loaded OGP or FN, loading OGP followed by $\mathrm{FN}$ led to a significant increase in proliferation level and late differentiation (Figures 7, 9, and 10), but no significant change in ALP activity (Figure 8). In the early stage of differentiation, the ALP levels between singly loaded FN and OGP were similar, which is consistent with previous studies, in which, besides promoting osteocyte attachment, FN also triggered early osteogenic differentiation with matrix formation via integrin-mediated signaling pathways. ${ }^{33}$ A single molecule can have some effects on signaling pathways. In the cellular environment, signaling is not limited to a single molecule, but can involve a variety of molecules with different bioactivities at different times. The simultaneously adsorbed OGP and FN may have had a synergistic effect, whereby ALP enhancement was amplified, as the rMSCs were exposed to OGP and FN at the same time. However, when rMSCs encounter FN first, then 
Table 2 Influences of factors on the levels of rMSC proliferation and osteogenic differentiation

\begin{tabular}{llll}
\hline & $\begin{array}{l}\text { Adsorption vs coprecipitation } \\
\text { of OGP }\end{array}$ & $\begin{array}{l}\text { Dually loaded OGP and FN vs single } \\
\text { loaded OGP or FN }\end{array}$ & $\begin{array}{l}\text { Adsorption vs coprecipitation } \\
\text { of OGP with adsorbed FN }\end{array}$ \\
\hline Proliferation & - & + & - \\
ALP activity & - & $+(\mathrm{aOF}) /-(\mathrm{cO} / \mathrm{aF})$ & + \\
OC secretion & + & + & + \\
Calcium deposition & + & + & + \\
\hline
\end{tabular}

Notes: +, significant increase; -, no significant difference.

Abbreviations: ALP, alkaline phosphatase; OC, osteocalcin; cO/aF, mineralization, coprecipitation of mineral and OGP, FN adsorption; aOF, mineralization, OGP and FN adsorption; OGP, osteogenic growth peptide; FN, fibronectin; rMSC, rat mesenchymal stem cell.

OGP is not sufficient to further promote early differentiation, as the sample with the $\mathrm{cO} / \mathrm{aF}$.

Differences in the methods of loading OGP with adsorbed FN also significantly impacted the osteogenic activity of rMSCs. Simultaneously adsorbed OGP and FN led to higher ALP levels, OC expression, and mineral deposition compared with coprecipitated OGP followed by adsorbed FN. The better performance with aOF was most likely due to more sustained release of adsorbed OGP, as discussed earlier.

The function of dually loaded OGP and FN on osteogenic activity is considered to be as follows. The absorbed FN enhances cell attachment and spreading on the substrates, thereby enlarging the contact area between the cells and the substrates. ${ }^{34}$ Sufficient cell adhesion is a mandatory precondition for further cell proliferation and differentiation. ${ }^{35}$ Via the tight binding between the ligands of the $\mathrm{FN}$ and receptors on the cell surfaces, a stagnant microenvironment is generated at the enlarged contact area between the cell surfaces and the substrates. Such formed microenvironment is enriched with OGP released from substrates. The presence of suboptimal or optimal levels of exogenous soluble OGP stimulates the increase in endogenous OGP expressed from rMSCs, ${ }^{36}$ which activates an intracellular Gi-protein-MAP kinase-signaling pathway. ${ }^{37}$

All in vitro results indicated that simultaneously adsorbed OGP and FN leads to the best cell responses in terms of cell attachment, proliferation, and osteogenic differentiation. As it is simple and easy to prepare in clinic, clinicians could make a spontaneous decision about whether to include the BMs based on the needs of the particular patient. This method could also reduce the risk of contamination and denaturation of the BMs.

\section{Conclusion}

The effects of different loading methods on the release kinetics of OGP, as well as rMSC responses to loaded OGP with and without adsorbed FN, were investigated. The release pattern of either coprecipitation or adsorption demonstrated biphasic release kinetics. Coprecipitation slightly reduced the initial burst release, while adsorption provided a more sustained release. In terms of the effects of loading method on rMSCs, the adsorbed OGP led to higher OC secretion and matrix mineralization compared with coprecipitated OGP. The dual loading of OGP and FN markedly enhanced rMSC adhesion and spreading, and also had significant effects on rMSC proliferation and osteogenic differentiation, compared to individual loading of OGP or FN.

\section{Acknowledgments}

This research was supported partly by the Basic Science Research Program through the National Research Foundation of Korea (NRF) funded by the Ministry of Education, Republic of Korea (2012R1A1A2040717), partly by Zhejiang Provincial Top Key Discipline of Biology, and partly by ZSTU-Scientific Research Foundation (13042158-Y).

\section{Disclosure}

The authors report no conflicts of interest in this work.

\section{References}

1. Kim H, Choi SH, Chung SM, Li LH, Lee IS. Enhanced bone forming ability of SLA-treated Ti coated with a calcium phosphate thin film formed by e-beam evaporation. Biomed Mater. 2010;5(4):044106.

2. Vandamme $\mathrm{K}$, Holy $\mathrm{X}$, Bensidhoum $\mathrm{M}$, et al. In vivo molecular evidence of delayed titanium implant osseointegration in compromised bone. Biomaterials. 2011;32(14):3547-3554.

3. Tsukimura N, Yamada M, Iwasa F, et al. Synergistic effects of UV photofunctionalization and micro-nano hybrid topography on the biological properties of titanium. Biomaterials. 2011;32(19):4358-4368.

4. Li Y, Lee IS, Cui FZ, Choi SH. The biocompatibility of nanostructured calcium phosphate coated on micro-arc oxidized titanium. Biomaterials. 2008;29(13):2025-2032.

5. Chen C, Qiu ZY, Zhang SM, Lee IS. Biomimetic fibronectin/mineral and osteogenic growth peptide/mineral composites synthesized on calcium phosphate thin films. Chem Commun (Camb). 2011;47(39): 11056-11058.

6. Sverzut AT, Crippa GE, Morra M, de Oliveira PT, Beloti MM, Rosa AL. Effects of type I collagen coating on titanium osseointegration: histomorphometric, cellular and molecular analyses. Biomed Mater. 2012; 7(3):035007.

7. Kang Y, Kim S, Khademhosseini A, Yang Y. Creation of bony microenvironment with $\mathrm{CaP}$ and cell-derived $\mathrm{ECM}$ to enhance human bone-marrow MSC behavior and delivery of BMP-2. Biomaterials. 2011;32(26):6119-6130

8. Yamachika E, Tsujigiwa H, Matsubara M, et al. Basic fibroblast growth factor supports expansion of mouse compact bone-derived mesenchymal stem cells (MSCs) and regeneration of bone from MSC in vivo. J Mol Histol. 2012;43(2):223-233. 
9. Hu Y, Cai K, Luo Z, et al. Regulation of the differentiation of mesenchymal stem cells in vitro and osteogenesis in vivo by microenvironmental modification of titanium alloy surfaces. Biomaterials. 2012;33(13):3515-3528.

10. Chen C, Lee IS, Zhang SM, Yang HC. Biomimetic apatite formation on calcium phosphate-coated titanium in Dulbecco's phosphate-buffered saline solution containing $\mathrm{CaCl}(2)$ with and without fibronectin. Acta Biomater. 2010;6(6):2274-2281.

11. Gabet Y, Müller R, Regev E, et al. Osteogenic growth peptide modulates fracture callus structural and mechanical properties. Bone. 2004;35(1):65-73

12. Bab I, Chorev M. Osteogenic growth peptide: from concept to drug design. Biopolymers. 2002;66(1):33-48.

13. Schwarzbauer JE, Sechler JL. Fibronectin fibrillogenesis: a paradigm for extracellular matrix assembly. Curr Opin Cell Biol. 1999;11(5):622-627.

14. Ripamonti U, Roden LC, Renton LF. Osteoinductive hydroxyapatitecoated titanium implants. Biomaterials. 2012;33(15):3813-3823.

15. Lee M, Li W, Siu RK, et al. Biomimetic apatite-coated alginate/ chitosan microparticles as osteogenic protein carriers. Biomaterials. 2009;30(30):6094-6101.

16. Perets A, Baruch Y, Weisbuch F, Shoshany G, Neufeld G, Cohen S. Enhancing the vascularization of three-dimensional porous alginate scaffolds by incorporating controlled release basic fibroblast growth factor microspheres. J Biomed Mater Res A. 2003;65(4):489-497.

17. Chen $\mathrm{C}$, Zhang SM, Lee IS. Immobilizing bioactive molecules onto titanium implants to improve osseointegration. Surf Coat Technol. 2013;228(Suppl 1):S312-S317.

18. Ziegler J, Mayr-Wohlfart U, Kessler S, Breitig D, Gunther KP. Adsorption and release properties of growth factors from biodegradable implants. J Biomed Mater Res. 2002;59(3):422-428.

19. Yazaki Y, Oyane A, Tsurushima H, et al. Coprecipitation of DNA-lipid complexes with apatite and comparison with superficial adsorption for gene transfer applications. J Biomater Appl. 2014;28(6):937-945.

20. Du C, Schneider GB, Zaharias R, et al. Apatite/amelogenin coating on titanium promotes osteogenic gene expression. J Dent Res. 2005;84(11): 1070-1074.

21. Luong LN, Hong SI, Patel RJ, Outslay ME, Kohn DH. Spatial control of protein within biomimetically nucleated mineral. Biomaterials. 2006;27(7):1175-1186.

22. Yu X, Wei M. Controlling bovine serum albumin release from biomimetic calcium phosphate coatings. J Biomater Nanobiotechnol. 2011;2(1):28-35.

23. Clem WC, Chowdhury S, Catledge SA, et al. Mesenchymal stem cell interaction with ultra-smooth nanostructured diamond for wear-resistant orthopaedic implants. Biomaterials. 2008;29(24-25):3461-3468.

24. Hu Y, Cai K, Luo Z, et al. Surface mediated in situ differentiation of mesenchymal stem cells on gene-functionalized titanium films fabricated by layer-by-layer technique. Biomaterials. 2009;30(21):3626-3635.
25. Lock J, Liu H. Nanomaterials enhance osteogenic differentiation of human mesenchymal stem cells similar to a short peptide of BMP-7. Int J Nanomedicine. 2011;6:2769-2777.

26. Yazaki Y, Oyane A, Sogo Y, Ito A, Yamazaki A, Tsurushima H. Control of gene transfer on a DNA-fibronectin-apatite composite layer by the incorporation of carbonate and fluoride ions. Biomaterials. 2011; 32(21):4896-4902.

27. Wu Z, Feng B, Weng J, Qu S, Wang J, Lu X. Biomimetic apatite coatings on titanium coprecipitated with cephradine and salviae miltlorrhizae. J Biomed Mater Res B Appl Biomater. 2008;84(2):486-492.

28. Barrère F, van der Valk CM, Dalmeijer RA, van Blitterswijk CA, de Groot K, Layrolle P. In vitro and in vivo degradation of biomimetic octacalcium phosphate and carbonate apatite coatings on titanium implants. J Biomed Mater Res A. 2003;64(2):378-387.

29. Yu X, Qu H, Knecht DA, Wei M. Incorporation of bovine serum albumin into biomimetic coatings on titanium with high loading efficacy and its release behavior. J Mater Sci Mater Med. 2009;20(1):287-294.

30. Mendes LS, Saska S, Martines MA, Marchetto R. Nanostructured materials based on mesoporous silica and mesoporous silica/apatite as osteogenic growth peptide carriers. Mater Sci Eng C Mater Biol Appl. 2013;33(7):4427-4434.

31. Spreafico A, Frediani B, Capperucci C, et al. Osteogenic growth peptide effects on primary human osteoblast cultures: potential relevance for the treatment of glucocorticoid-induced osteoporosis. J Cell Biochem. 2006;98(4):1007-1020.

32. Stakleff KS, Lin F, Smith Callahan LA, et al. Resorbable, amino acidbased poly(ester urea)s crosslinked with osteogenic growth peptide with enhanced mechanical properties and bioactivity. Acta Biomater. 2013;9(2):5132-5142.

33. Seo CH, Jeong H, Feng Y, et al. Micropit surfaces designed for accelerating osteogenic differentiation of murine mesenchymal stem cells via enhancing focal adhesion and actin polymerization. Biomaterials. 2014;35(7):2245-2252.

34. Oyane A, Murayama M, Yamazaki A, Sogo Y, Ito A, Tsurushima H. Fibronectin-DNA-apatite composite layer for highly efficient and area-specific gene transfer. J Biomed Mater Res A. 2010;92(3):1038-1047.

35. Anselme K. Osteoblast adhesion on biomaterials. Biomaterials. 2000; 21(7):667-681.

36. Greenberg Z, Chorev M, Muhlrad A, et al. Structural and functional characterization of osteogenic growth peptide from human serum: identity with rat and mouse homologs. J Clin Endocrinol Metab. 1995;80(8):2330-2335.

37. Gabarin N, Gavish H, Muhlrad A, et al. Mitogenic G(i) proteinMAP kinase signaling cascade in MC3T3-E1 osteogenic cells: activation by $\mathrm{C}$-terminal pentapeptide of osteogenic growth peptide [OGP(10-14)] and attenuation of activation by cAMP. J Cell Biochem 2001;81(4):594-603
International Journal of Nanomedicine

\section{Publish your work in this journal}

The International Journal of Nanomedicine is an international, peerreviewed journal focusing on the application of nanotechnology in diagnostics, therapeutics, and drug delivery systems throughout the biomedical field. This journal is indexed on PubMed Central, MedLine, CAS, SciSearch $®$, Current Contents $\AA /$ Clinical Medicine,

\section{Dovepress}

Journal Citation Reports/Science Edition, EMBase, Scopus and the Elsevier Bibliographic databases. The manuscript management system is completely online and includes a very quick and fair peer-review system, which is all easy to use. Visit http://www.dovepress.com/ testimonials.php to read real quotes from published authors. 